\title{
The Effect of Ball Size Diameter on Milling Performance
}

\author{
Kabezya KM* and Motjotji $\mathrm{H}$ \\ Lecturer, University of the Witwatersrand, Johannesburg, Gauteng, South Africa
}

\begin{abstract}
An investigation was conducted to determine the effect of the ball diameter sizes on milling operation. A laboratory size ball mill was used with ball media of sizes $10 \mathrm{~mm}, 20 \mathrm{~mm}$ and $30 \mathrm{~mm}$ respectively. Quartz was the material used to perform the experiment and was arranged into 3 mono-sizes namely $-8 \mathrm{~mm}+5.6 \mathrm{~mm},-4 \mathrm{~mm}+2.8 \mathrm{~mm}$ and-2 $\mathrm{mm}+1.4 \mathrm{~mm}$ for the experiment. A mill run having a mixture of the 3 ball diameter sizes was also conducted. It was determined that the $30 \mathrm{~mm}$ diameter balls were most effective of the three sizes during the grinding of the 3 monosize feed material samples. The $10 \mathrm{~mm}$ diameter balls were the least effective as minimum particle breakage was observed whereas the $20 \mathrm{~mm}$ diameter balls were relatively effective to some extent. The selection function of the $30 \mathrm{~mm}$ balls was also much greater as it had a higher maximum point and a very low small abnormal region. The mill run conducted using a mixture of ball sizes however was slightly better than that of the 30 mm diameter balls. The primary breakage function was observed as to be non-related to the ball diameter but rather to the 3 mono-sizes of the feed material. In terms of the power draw, there seemed to be no link between it and the ball diameter size.
\end{abstract}

Keywords: Milling; Efficiency; Balls; Size; Operation; Performance; Optimization

\section{Introduction}

Milling is the third and final stage of comminution after crushing which involves the reduction of solid particle sizes to micron size level. The size reduction is achieved by a combination of abrasive and impact forces between the particles and the milling media as well as the walls of the mill [1]. Ball mills are one of the most commonly used milling equipment in minerals processing due to the extensive size reduction (reduction ratio) they can achieve [2]. It is however widely determined that ball mills have very low efficiencies in terms of the utilization of the generated energy towards milling. Approximately only about $20 \%$ of the energy generated by the mill is utilized for actual grinding of the ore [2]. This inefficiency is a result of various factors such mill load, rotation speed, type of milling (wet or dry) as well as the size of the steel balls [3]. Mills are also one of the largest energy consumers in processing plants which can be estimated to about $50 \%$ of the total energy utilized in minerals processing. This therefore indicates that it is very vital that mills operate under optimum conditions $[2,3]$. The size of the steel balls used during the milling process are related to the size of the mill charge material whereby small diameter balls are used for feed material of small sizes while larger diameter balls are used for larger sized feed material [4]. It is also necessary to consider the optimum load of a mill when considering the ball diameter. Magdalinovic also suggests that larger diameter balls have more energy whereas balls having smaller diameters have less energy. These different energies are however relative to the optimum ball diameter, which differs according to the size of the mill as well as the desired size reduction of the feed material $[3,4]$.

A mill is a type of rotating or tumbling cylindrical drum which rotates around its own axis thus performing an abrasion and impacting action of the milling media and ore particles inside [2]. The rotation motion is achieved by means of an electric motor which can be configured to various rotational speeds depending on the size of the mill as well as the type of mill load motion required. Milling can either be done wet or dry whereby for wet milling, a fluid such as water is added during the milling process. For dry milling, the charge material contains about less than $1 \%$ moisture or water content whereas for wet milling, the moisture or water content is greater than $34 \%$ by volume [5]. Wet milling requires less energy, consumes less power and can achieve a higher degree of size reduction compared to dry milling [6]. Dry milling is however preferred over wet milling due to the difficulty associated with the handling of a wet slurry during milling [5]. Ball mills can be used in a variety of industries such as the minerals processing, metallurgy, mining, chemicals, agriculture, plastics, and the food industry, among others [7]. This is due their simplicity and effectiveness during application [2,8]. Ball mills also tend to have a greater reduction ratio as well as a lower rate of reduction, thus making them more preferable over other kinds of mills [2]. But like any of the other mills, as previously mentioned ball mills have a very low efficiency in terms of utilizing the energy generated towards particle size reduction. The diameter of the balls used in ball mills play a significant role in the improvement and optimization of the efficiency of the mill [4]. The optimum rotation speed of a mill, which is the speed at which optimum size reduction takes place, is determined in terms of the percentage of the critical speed of the mill [8]. The critical speed is the speed at which the mill load sticks to the walls of the mill during rotation. The aim of this project was to determine the effect of the ball diameter on the operating parameters of the mill, which included the energy efficiency, the power requirement, mill load, critical speed as well as the size reduction of the mill charge. It was thus required that these mentioned operating parameters be optimized by experimentally determining the most appropriate ball diameter so as to obtain the desired energy.

\section{Experimental Procedure}

A laboratory size ball mill of diameter $30 \mathrm{~cm}$ was used with ball media of sizes $10 \mathrm{~mm}, 20 \mathrm{~mm}$ and $30 \mathrm{~mm}$ respectively as shown in Figure 1. Quartz was the material used to run experiments, and was arranged into 3 mono-sizes namely $-8 \mathrm{~mm}+5.6 \mathrm{~mm},-4 \mathrm{~mm}+2.8 \mathrm{~mm}$

*Corresponding author: Kabezya KM, Wits University, Johannesburg, Gauteng, South Africa, Tel: 0117177522; E-mail: kitungwa.kabezya@wits.ac.za

Received November 20, 2014; Accepted January 13, 2015; Published January 22, 2015

Citation: Kabezya KM, Motjotji H (2015) The Effect of Ball Size Diameter on Milling Performance. J Material Sci Eng 4: 149. doi:10.4172/2169-0022.1000149

Copyright: (c) 2015 Kabezya KM, et al. This is an open-access article distributed under the terms of the Creative Commons Attribution License, which permits unrestricted use, distribution, and reproduction in any medium, provided the original author and source are credited. 


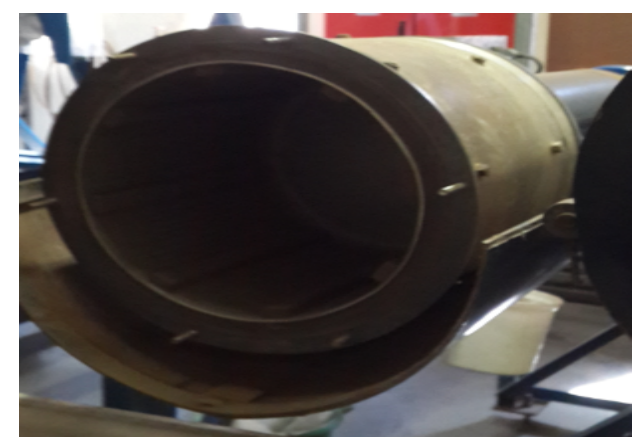

Figure 1: Image of the mill used for this experiment.

and $-2 \mathrm{~mm}+1.4 \mathrm{~mm}$ for experiments. A mill run having a mixture of the 3 ball diameter sizes was also conducted.

The ball filling level was kept constant at $40 \%$ by volume for all ball diameters as was done by Magdalinovic. The rotational speed of the mill was kept at $85 \%$ of the critical speed. The sample ore charge, Q, was such that the ore sample completely filled the voids or interstitial spaces between the balls, meaning that the mass of the charge varied with the ball diameters [4]. The residence time was material dependent and thus depended on the grindability or hardness of the sample ore.

The products from the four milling processes were screened using a range of different aperture screens to determine the extent of size reduction (comminution ratio) as well as the size distribution of the product samples after each of the four milling processes. For the milling process, the $30 \mathrm{~mm}$ diameter balls were first used, the mill was loaded with $29.06 \mathrm{~kg}$ of the balls as calculated and then $2.7 \mathrm{~kg}$ of a quarts sample in the size class $-8 \mathrm{~mm}+5.6 \mathrm{~mm}$ was then loaded into the mill. The mill was first run for 30 seconds and then the entire mill load was removed and then a 100 gram sample was taken from the quarts sample using the spinning rifle. The remaining sample was then loaded into the mill along with the $30 \mathrm{~mm}$ balls and the mill was run for an additional 1 minute, thus making up the second mill run interval of 1 minute 30 seconds. A 100 gram sample was once again taken for this particular milling interval. Once again the remaining sample was reloaded into the mill and the mill was run for 2 minutes 30 seconds to make up the 4 minute mill run interval. The sampling procedure was once again repeated with a 100 gram sample being taken from the sample. This procedure was repeated for the other samples in the size classes $-4 \mathrm{~mm}+2.8 \mathrm{~mm}$ and $-2 \mathrm{~mm}+1.4 \mathrm{~mm}$ respectively. The $20 \mathrm{~mm}$ and $10 \mathrm{~mm}$ diameter balls were also used during the milling following the above mentioned procedure. Another mill run was performed using a combination of the three ball diameters and the same milling and sample process was followed

\section{Results and Discussion}

After milling for 4 minutes, the points on cumulative \% passing curves appeared to have a broader distribution, indicating more particle breakage. The $30 \mathrm{~mm}$ ball diameter and the ball combination categories showed better results compared to the $20 \mathrm{~mm}$ and $10 \mathrm{~mm}$ as highlighted in Figure 2. This therefore indicated that the large ball diameters were more effective when milling this particular material size class. To further support the statement made by Katubilwa et al. which stated that larger feed material size would require larger ball diameters during milling, Figure 3 below shows the cumulative 5 passing curve for a feed material of size $-2 \mathrm{~mm}+1.4 \mathrm{~mm}$ when milled under the same conditions. From Figure 3, it was observed that the particle size distribution when milling with $20 \mathrm{~mm}$ and the $10 \mathrm{~mm}$ diameter balls started spreading out thus showing a wider distribution of different sized particles. The $30 \mathrm{~mm}$ ball diameter milling still performed better than the small ball diameters, but the performance for this ball size had decreased for the $-2 \mathrm{~mm}+1.4 \mathrm{~mm}$ mono-size feed compared to the bigger $-4 \mathrm{~mm}+2.8 \mathrm{~mm}$ mono-size feed. This therefore shows that should the material feed size continue to decrease, the smaller balls will perform better than the larger balls during milling, as was mentioned by Katubilwa et al.

\section{Effect of ball diameter size on mill power draw}

The mill power draw for each mill run was determined from the voltage required by the mill motor average voltage and torque.

To take a closer look at the relationship between the power draw and the ball diameter, Figure 4 below was plotted using data from 4 mill revolutions for which the milling duration was 4 seconds. As could be seen from the Figure 4, there seemed to be no trend for the power draw with regards to the ball diameter. This might be due to the fact that the power draw depended mostly on the mill load and the type of lifters fitted into the mill [9].

The oscillations observed on the graph were a result of an increase and decrease in energy required during the tumbling of the mill and its contents. As the mill load was lifted by the lifters, energy was required and therefore we observe an increase in the power draw and as the load was dropped onto the mill toe, energy was released and the power

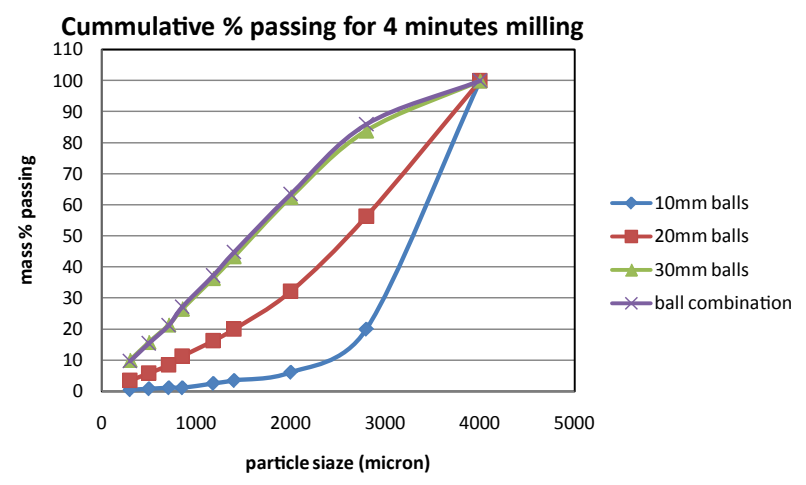

Figure 2: Graph showing the cumulative mass \% passing for milling the $-4 \mathrm{~mm}+2.8 \mathrm{~mm}$ feed size for 4 minutes.

cummulative \% passing for 4 minutes milling

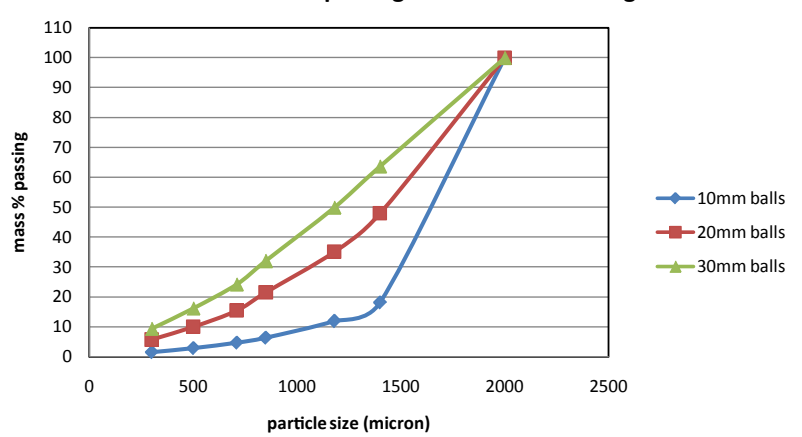

Figure 3: Graph showing the cumulative mass \% passing for milling the $-2 \mathrm{~mm}+1.4 \mathrm{~mm}$ feed size for 4 minutes. 


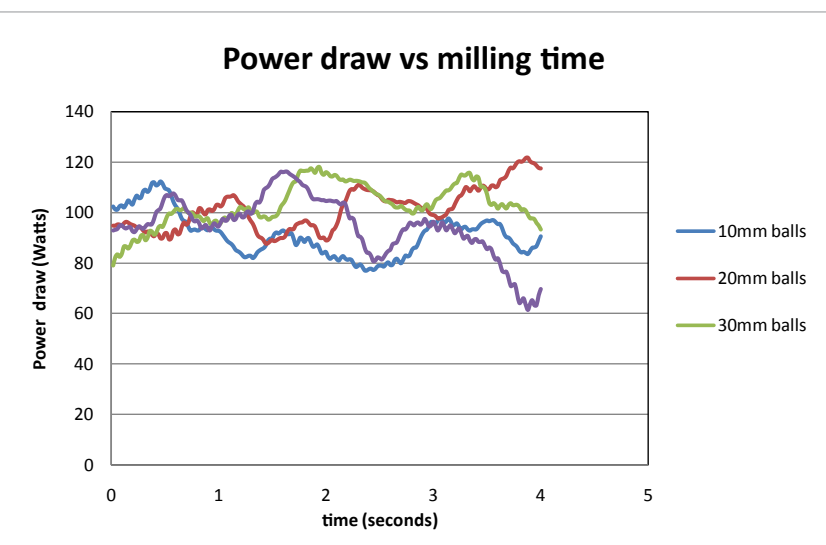

Figure 4: Graph showing the power draw for four mill revolutions over 4 seconds.

draw decreased [10]. It was thus observed that the oscillations for the 3 ball diameters remain between 80 and 120 watts. An interesting observation however was that the power draw for the $20 \mathrm{~mm}$ balls appeared to be increasing even though the mill load for that mill run was lower. This was unusual because literature stated that higher mill loads experienced a higher power draw [11]. The power draw for the ball combination mill run appeared to be decreasing to a large extent. This therefore indicated that this particular mill run was the more energy efficient compared to the other mill run

\section{Conclusion}

It could be concluded that in terms of the milling kinetics, large ball diameters were more suitable for milling larger material whereas small ball diameters would be more effective at milling smaller sized material. This was evident on the cumulative \% passing curves whereby the plot obtained when milling with larger ball diameters $(30 \mathrm{~mm}$ and ball combination) was more distributed compared to the curves obtained from milling with smaller diameter balls $(20 \mathrm{~mm}$ and $10 \mathrm{~mm})$ The maximum point on the selection function plots for larger ball diameters was greater than that of small ball diameters and the abnormal region for the smaller ball diameters was also larger compared to larger ball diameters. The abnormal region indicates a region whereby the ball sizes are not big enough to cause particle breakage during milling. The ball combination mill runs showed the best results in terms of particle size distribution, selection function as well as the breakage function. In terms of the power draw, there seemed to be no link between it and the ball diameter size and it was already established earlier that the power draw depends on the mill loading. It was however observed that the power draw for the $20 \mathrm{~mm}$ balls seemed to be following an increasing trend even though the mill loading for when using the $20 \mathrm{~mm}$ balls was lower. The power draw for the ball combination mill run displays a decreasing trend and thus was the most efficiency with regards to the utilization of power towards particle breakage.

\section{References}

1. Wills NM (2006) Grinding Mills. In TN M, Wills BA (eds) Will's Mineral Processing technology. Johannesburg: Elsevier science and Technology books.

2. Melero CN (2014) Electric motors monitoring: An alternative to increase the efficiency of ball mills. International Conference on Renewable Energies and Power Quality.

3. Lameck NN (2005) Effects of Grinding Media Shapes on Ball Mill Performances Johannesburg, Gauteng, South Africa: University of the Witwatersrand.

4. Magdalinovic N, Trumic M, Trumic M, Andric L (2012) The Obtimal Ball Diameter in a Mill. Physico Chem Probl Miner Process 48: 329-339

5. Kalemtas A (2014) Ceramic Materials

6. Fuerstenau, Sullevan (2014, July 22). Retrieved from www.onemine.org

7. http://www.onemine.org/search/summary.cfm/Minerals-Beneficiation-Size-Distributions-and-Energy-Consumption-in-Wet-and-DryGrinding?d=1234567890

8. Monov V, Sokolov B, Stoenchev S (2012) Grinding in Ball Mills: Modeling and Process Control. Cybernetics and Information Technologies 12: 51-68.

9. Sahoo GK (2008) Correlations for the Grindability of the Ball Mill as a Measure of its Performance. Asia Pacific Journal of Chemical Engineering 3: 230-235.

10. Fortsch DS (2006) Ball charge Loading - Impact on specific power consumption and capacity. Cement Industry Technical Conference, Conference Record.

11. Bwalya (2014) Supervisor Consultation. 